\title{
Marta Irurozqui \\ Herencias escamoteadas. Una reflexión sobre los procesos de politización y de incorporación nacional de la población indígena, siglo $\mathrm{XIX}^{1}$
}

Las decisiones políticas tomadas por el gobierno de Evo Morales, líder del Movimiento al Socialismo (MAS), no sólo revelan que los problemas de disgregación social y de cohesión interna se perciben vinculados con los temas cultural y étnico, sino que también han reabierto la discusión en torno al papel desempeñado por la población englobada bajo las categorías india/indígena/originaria en la construcción nacional boliviana. Dado el clima de polarización política que por motivos de índole diversa vive el país, hasta el momento el tema se ha manejado públicamente en clave revanchista, xenófoba y maniquea con la consiguiente sublimación del discurso acerca de que este colectivo ha sido marginado sistemáticamente del mundo político. Tal narrativa se sustenta a través tanto de subrayar el carácter excluyente de los proyectos nacionales bolivianos, como de defender una identidad inmutable india que los convierte en integrantes de una nación histórica ajena al Estado nacional existente.

En esta lectura de lo indígena convergen diversos ingredientes. Primero, se produce una extrapolación mecánica al pasado de preocupaciones, percepciones y prejuicios actuales, que está sustentada tanto en una lógica lineal y evolucionista de la Historia, como en un uso político de la misma para legitimar proyectos nacionalistas o étniconacionales (Quijada 2004: 9-23; García Jordán 2006: 24-25). Segundo, no sólo existe un enorme desconocimiento historiográfico sobre la acción india en los procesos de configuración nacional, sino que además se ignora que el vínculo indio/víctima en gran medida responde (al igual que sus otras facetas de "apolítico, premoderno, criminal o identitariamente inmutable") a construcciones historiográficas elitistas

1 Proyectos de investigación I+D: HUM2006-01703/CISO y HUM2006-10136. 
formalizadas en la segunda mitad del siglo XIX que han permeado, unas veces acrítica y otras interesadamente, las interpretaciones académicas de los siglos XX y XXI, las posiciones ideológicas y las acciones políticas consecuentes (Salmón 1997; Barragán 2000; Irurozqui 2008b). Frente a ello, en los últimos años, la revitalización y renovación historiográfica de lo político ha obligado a repensar el papel de esta población en la vida nacional. Si bien ello ha contribuido a debilitar el tópico de que el proyecto de Estado-nación boliviano fracasó debido al intento criollo-mestizo de constituir una nación a partir de la negación de los derechos del ciudadano moderno a la gran mayoría de la población, aún se mantienen inercias historiográficas. Éstas favorecen que, bajo el fácil peso de los binomios indio/pobreza, indio/explotación e indio/marginación, se siga poniendo el acento en la capacidad excluyente o perversa de las instituciones republicanas, se insista en una identidad indígena monolítica o se ponga en duda su participación en la construcción nacional como agentes interesados en la misma por presuponerse que tal proceso había sido siempre contrario y perjudicial a la conservación de su identidad grupal y a su devenir histórico.

Ante esa narrativa dominante que, desde la culpa, el menosprecio o el oportunismo político, persiste en tratar al indígena como una víctima naturalizada, este texto quiere poner en valor su dimensión histórica de sujeto político. En ningún caso se trata de atenuar las marginaciones y sinsabores de las que ha sido objeto, sino de insistir, desde la complejidad y ambigüedades que conlleva toda categoría identitaria, en que éstas se sustentan en factores múltiples y, en ocasiones, contradictorios que no sólo no impidieron a esta población formar parte activa de la construcción nacional boliviana, sino que la forzaron a hacerlo. De ahí que el propósito de este texto sea incidir en su centralidad en lo relativo a la definición gubernamental a partir de la discusión de dos tópicos: la exclusión absoluta de los indios de la sociedad y el desinterés de éstos en insertarse en la nación e influir en el desarrollo de políticas públicas. Tales prejuicios serán cuestionados mediante una exposición sobre el modo en que a lo largo del siglo XIX fue entendida la ciudadanía, sobre la manera en que ésta debía ser adquirida por la población y sobre las soluciones indígenas al respecto. 


\section{Precisiones conceptuales ${ }^{2}$}

Por razones de espacio es imprescindible advertir al lector que la interpretación que se ofrece sobre el proceso de politización nacional indígena se sustenta en una serie de reflexiones teóricas sobre la ciudadanía desarrolladas en otros trabajos, tendentes a desentrañar equívocos epistemológicos y a subrayar su naturaleza historizable como concepto: primero, la tamización de la vocación igualitaria y universalista de la ciudadanía; segundo, el cuestionamiento de su reducción nominal al voto; y, tercero, la insistencia en la naturaleza no necesariamente excluyente del sufragio censitario a causa de dos variables interactivas -el carácter redistributivo y de enraizamiento socioterritorial de la vecindad y un contexto estatal de fe ilimitada en las capacidades liberadoras y transformadoras de las instituciones. A ello se suma la aseveración de que fuera del Estado resultaba precaria la posibilidad política y social del disfrute de la ciudadanía por parte de la población.

En consonancia con lo mencionado, la ciudadanía se entiende como una práctica y como un estatus. Por un lado, denota una forma de participación activa en los asuntos públicos; por otro, implica una relación de pertenencia individual con una determinada comunidad política, convirtiéndose, así, en un principio constitutivo propio de cada comunidad política que determina quién constituye ésta, quién pertenece a la misma y quién no. La ciudadanía es, por tanto, mucho más que un estatus formal jurídicamente establecido: es la cualidad de un miembro de la comunidad política, pero también es un vínculo de identidad y sobre todo, un título de poder que genera existencia social. De lo anterior se desprende que la ciudadanía no es un principio universalista, sino diferenciador. Funciona como un factor discriminatorio de inclusión/exclusión y, a su vez, como un dispositivo corporativista, combinación de los "privilegios que un individuo posee" y de su dependencia comunitaria. $\mathrm{Y}$ esto no significa que la ciudadanía se forje para sostener, desde lo jurídico, formas variadas de desigualdad de clase y de etnia, sino que su carácter integrador es cuestionable dada su naturaleza comunitaria. Recoge principios y exigencias universales que, sin embargo, se aplican en un ámbito concreto y en con-

2 Este apartado sintetiza los argumentos expresados en Irurozqui (2005a; 2005b; 2008a). 
diciones particulares. Es decir, la ciudadanía es también un instrumento de exclusión. Al estar definida como pertenencia a una comunidad, tal condición conlleva excluir hacia fuera y proteger con privilegios hacia dentro, siendo más fuerte esa tendencia cuanto mayor y más exigente sea el componente identitario.

De lo anterior se desprenden tres afirmaciones. Primera, fue esa naturaleza excluyente la que históricamente dio valor social a la ciudadanía y la que la convirtió en un objeto de deseo social. Segunda, la obtención de la ciudadanía exigió acciones públicas y políticas por parte de quienes la deseaban, siendo el ejercicio de la ciudadanía el creador de ciudadanos. Y, tercera, la ciudadanía no pudo crecer y adquirir prestancia pública y política sin su constante demanda. Tal actitud estuvo favorecida por el hecho de que el ocasional incumplimiento de lo normativo por parte del Estado o la sociedad no impidió su permanencia como referente fundamental para iniciar desde él cualquier proceso de reconquista legal. Las tres afirmaciones muestran que la ciudadanía posee un triple movimiento: exclusión-acción-inclusión. La exclusión no puede eliminarse como tendencia porque está implícita en el principio de comunidad, pero puede combatirse, corregirse y transformarse mediante la acción individual y colectiva dando lugar a un proceso inclusivo nunca inconcluso que provoca una revisión constante de la naturaleza de la igualdad entre más de dos sujetos. Ello obliga a recordar el carácter contingente de la ciudadanía y a interpretarla como un producto histórico de luchas políticas y públicas, en vez de asumirla como algo graciosamente otorgado producto de un progreso lineal y teleológico. En consecuencia, la noción de ciudadanía remite a un estado social de aceptación y reconocimiento públicos y de integración territorial que en tanto práctica implicaba una constante iniciativa particular de intervención, participación y gestión de lo público. Tales actos se ejercitaban tanto bajo el amparo de las leyes, como mediante la vulneración de las mismas, ya que el quiebre de la exclusión mediante la acción provenía de una combinación de las medidas institucionales con las iniciativas sociales de carácter subversivo.

La mencionada doble condición de estatus y de práctica política de la ciudadanía incidió en el modo en que históricamente fueron interactuando los dos componentes jurídico-formales de esta institución: los deberes y derechos legalmente reconocidos de la población de un Estado nacional. El dominio de los primeros dio lugar a la ciudadanía 
cívica, constituida por sujetos colectivamente comprometidos con su medio, cuyos derechos procedían del libre e individual ejercicio de las obligaciones comunitarias; mientras que el peso de los segundos constituyó a la ciudadanía civil, integrada por consumidores o detentadores exclusivos de derechos, quienes para su disfrute no estaban obligados al cumplimiento de "cargas" colectivas o a la demostración de méritos comunitarios. ¿Cómo afectó esa variación ciudadana a los indígenas? Como argumento central se sostendrá que, al contrario de lo planteado por una concepción evolucionista de la historia, la población indígena vio formalmente -no legalmente- mermado el reconocimiento de sus capacidades públicas a medida que avanzaba el siglo XIX. Esa pérdida gradual de entidad ciudadana, en vez de silenciarla, la obligó a apelar a las narrativas republicana, liberal y democrática para recuperar espacios de actuación, siendo tal acción la que propició su compromiso e ingerencia en la construcción nacional. En consecuencia, el proceso de ciudadanización y desciudadanización experimentado por los indígenas se aborda a través del estudio de los procedimientos cívicos empleados por los indios para reivindicar su adscripción a la categoría de ciudadano. A lo largo del siglo XIX, ésta se materializó mediante su autoidentificación progresiva como sujetos patriotas y nacionalmente productivos: trabajadores, contribuyentes y soldados de milicias. Entendieron que el ejercicio de tales figuras les proporcionaría no sólo dignificación y existencia sociales, sino también escenarios para reinventarse como servidores del Estado, posibilitándoles ello la conversión de sus demandas grupales y locales en nacionalmente legítimas. Aunque no se va a desarrollar aquí, es preciso indicar que a partir de la década de $1880 \mathrm{y}$, sobre todo, de la de 1900 el progresivo agotamiento de las funciones mencionadas como formas de revitalización pública les llevaría a intensificar las acciones políticas ligadas a los partidos políticos y a las contiendas electorales.

\section{Los patriotas generan riqueza: trabajadores y contribuyentes ${ }^{3}$}

Como hasta la revolución de 1952 en Bolivia estuvo vigente con escasas modificaciones coyunturales el sufragio censitario, fue precisamente la hegemonía de la ciudadanía cívica o la ciudadanía civil lo

3 Este apartado sintetiza los argumentos expresados en Irurozqui (2000: 366-410; 2006a: 32-55). 
que marcó la interpretación práctica y local de la normativa legal y, por tanto, la que definió el diseño ideal del ciudadano y la que justificó lo que podía ser y hacer el gobierno, la ley y la sociedad en general. Así, mientras estuvo en vigencia el componente cívico de la ciudadanía, la adquisición del estatus de ciudadano no implicó ni requirió necesariamente segregaciones étnicas, de riqueza o de preeminencia social. Mientras el peso de lo local en la identificación del ciudadano relativizaba la dimensión de esas exigencias, cualquier acto de valor comunitario y patriótico poseía capacidad de redención ciudadana. Ello tornaba a la ciudadanía en una conquista individual a la que podían aspirar todos los sujetos que estuviesen dispuestos al sacrificio de sus ambiciones personales por el bien público. Tal comportamiento debía ser públicamente demostrado, ya que su exhibición sintetizaba el compromiso de un individuo con la patria. Convertida en un premio a la cooperación nacional, la ciudadanía hacía, en consecuencia, referencia a una comunidad unitaria definida por una tradición y experiencia comunes. Éstas no se concebían necesariamente como preexistentes, sino que podían adquirirse a través de comportamientos productivos o de actos bélicos. De ahí que a lo largo del siglo XIX cobraran importancia como fuente de dignificación ciudadanas tres figuras públicas: trabajador, contribuyente y soldado de milicias. Si bien éstas no adquirieron la misma relevancia a la vez, sí compartieron el principio de que para poder actuar a favor del engrandecimiento nacional era imprescindible que sus detentadores tuvieran conocimiento de lo público y posibilidad de modificarlo. $\mathrm{Y}$ esto quedaba asegurado a través de la capacidad de saber leer y escribir. ¿Qué se estableció al respecto? ${ }^{4}$

Si las Cortes de Cádiz concedieron a los indígenas el pleno estatuto de ciudadanía sin despojarlos de sus privilegios legales relativos a la posesión de tierras en régimen de comunidad, la Constitución Boliviana de 1826 revocó el sufragio universal masculino, dictaminándose que la ciudadanía sólo podían ejercerla los varones mayores de edad, alfabetos, con propiedad o renta no adquirida en calidad de domésti-

4 Las referencias documentales utilizadas acerca del criterio de saber leer y escribir en Redactor de la Asamblea Constituyente del año 1826. La Paz, Imp. y Lit. Boliviana Hugo Hartman y Cia. (1917): 418-420, 444-446, 451-452, 469, 447; los periódicos El Cóndor (1826-1829) y El Iris (1829-1838); Alcides D’Orbigny (1958): Viajes por Bolivia. Tomo I. La Paz: Ministerio de Educación/Bellas Artes. 
cos. ¿Cómo afectó esa medida a la población india? Cuando la Asamblea Constituyente de 1826 abordó el tema de la exigencia constitucional de saber leer y escribir, hubo diputados que apelaron a ese requisito para impedir el voto indígena bajo el argumento de que, como la soberanía en los gobiernos representativos no debía ejercerla todo el pueblo sino los que tuvieran "las luces suficientes para hacer su felicidad", su naturaleza iletrada les hacía estar a merced de cualquier influencia y seducción externas. Sin embargo, la mayoría de los miembros de la Asamblea estuvo en desacuerdo con su exclusión. Los argumentos que esgrimieron fueron tres. Primero, esta población ya había gozado del derecho al voto durante el gobierno constitucional español, luego impedirles su disfrute "podía acarrear mil males" al llevarles a comparar esa situación con la que iban a encontrarse "bajo un gobierno libre". Segundo, aunque la influencia social de los poderosos era inevitable, los indios, pese a su falta de ilustración, ya habían actuado con discernimiento, no sólo al levantarse en masa contra los españoles, sino también porque los actuales diputados habían sido electos "por los que lo fueron por esos hombres a quienes llaman enteramente estúpidos". Y, tercero, en el país había "infinidad de propietarios y de otros hombres de aptitudes" que eran analfabetos, de manera que si sólo la cuarta parte de los bolivianos sabía leer y escribir, iba a establecerse a una aristocracia del Estado, lo que sería contrario al principio de que la soberanía residía en el pueblo. Si éste lo componían todos los bolivianos, "siendo indígenas cuanto menos las dos terceras partes de estos" y siendo éstos "dueños del país y más naturales que los blancos", su exclusión no sólo sería contraria a la voluntad general sino que "extinguiría el principio motor de la prosperidad pública, que es el amor de la patria, pues que los indígenas no podrían amar a una patria que los desconoce".

La discusión entre los diputados evidenció que la exigencia de saber leer y escribir no estaba dirigida a los indios, con el objetivo de castigarlos o de "contraerlos", sino a todos los bolivianos iletrados. Con el convencimiento de que si esta población no participaba en todos los bienes de la sociedad, el pacto social respecto a ella sería nulo y de ningún valor, quedando la mayor parte del país sin representación, se acordó que "no era gracia sino justicia la que se haría a los indígenas y demás clases que se hallan en el mismo caso concediéndoles la ciudadanía". De ahí que se acordara posponer la exigencia del 
requisito de saber leer y escribir a la década de 1830. Como el descuido educativo de la época colonial no podía mantenerse bajo un régimen representativo, las instituciones estatales debían insuflar el espíritu público entre la población mediante el desarrollo de la instrucción pública. Pero la reducción del alto porcentaje de iletrados también dependía del esfuerzo personal. Si la extensión de la educación era responsabilidad del Estado, los bolivianos tenían que demostrar interés en su adquisición porque con ello probaban su voluntad de contribuir al bien general. En este sentido, el requisito de saber leer y escribir no buscaba discriminar entre "indígenas, blancos o negros", sino obligar a los bolivianos a tomar conciencia de su responsabilidad nacional. Ésta abarcaba tanto una exigencia al Estado de dignificar a la población dotándola de los conocimientos o medios necesarios, como una autoexigencia personal de aprender lo imprescindible para tener juicio propio y evitar influencias externas.

Establecido que ser letrado se asumía como un derecho que era obligatorio exigir y ejercer, ¿cómo demostraba un individuo su amor y compromisos patrióticos? ${ }^{5}$ De cara al proceso de institucionalización

5 Las referencias documentales a los temas de "trabajo y tributación" pertenecen a Redactor de la Asamblea Constituyente del año 1826. La Paz, Imp. y Lit. Boliviana Hugo Hartman y Cia. (1917: 418, 448-453); El Cóndor. Sucre, 10 de enero de 1828; 2 y 23 de febrero de 1826; 22 de marzo de 1826; 8 y 16 de marzo; 17, 18 y 24 de mayo; 27 de septiembre y 5 de octubre de 1827; El Iris. La Paz, 8 y 15 de agosto de 1829; 23 de marzo de 1830; 8 de mayo de 1830; 21 de agosto de 1830; 30 enero de $1831 ; 5$ de febrero de 1832; 15 de abril de $1832 ; 13$ y 20 de mayo de 1832; 24 de junio de 1832; 14 de julio de 1833; 23 de febrero de 1834; 2 y 9 de marzo de 1834; 10 de agosto de 1834; 7 de diciembre de 1834; 27 de diciembre de 1837; 8, 9 y 14 de enero de 1838; 4 de marzo de 1838; Colección oficial de leyes, decretos, órdenes, resoluciones, etc. que han sido expedidos para el régimen de la República de Bolivia. Tomos II, III, IV y V. La Paz de Ayacucho: Imp. del Colegio de Artes, 1832-1838, T. II, p. 33, T. III, pp. 125, 136-137, T. IV, pp. 251253, T. V, pp. 249-250; Colección Oficial de Leyes, decretos, órdenes de la República boliviana, años 1825-1826. La Paz: Imp. Artística, 1926: 102, 127; Colección oficial de leyes, decretos, órdenes y resoluciones supremas que se han expedido para el régimen de la República Boliviana. Impresa de orden del gobierno supremo con anotaciones y dos índices. Tomo V, Que comprende el año de 1838. Sucre, Imp. de López, 1857: 89-90; 379-382; Colección Oficial. Nueva Serie, I, p. 125; Daniel F. O'Leary (1919): Cartas de Sucre al libertador (1827-1830). Tomo II y último. Madrid: Ed. La América, pp. 111, 191; Bosquejo del estado en que se halla la riqueza nacional de Bolivia con sus resultados, presentado al examen de la nación por un aldeano hijo de ella. Año de 1830 (edición coordinada por Ana María Lema et al.). La Paz: Plural-UMSA, 1994, pp. 61-62. José María Dalence (1975): 
del Estado y a la generación de riqueza nacional resultaba imperioso, por un lado, sanear la hacienda pública y lograr la estabilidad financiera, y, por otro, crear crédito industrial a través de la modernización del agro. Tal prioridad explicaba por qué mientras el requisito de saber leer y escribir fue manejado por la Asamblea en clave de flexibilidad, no pudiese ocurrir lo mismo respecto a que no tener "industria o profesión". Esa condición se consideró contraria al mantenimiento del orden y la tranquilidad públicos. Sin "industria ni ejercicio" era imposible que un individuo profesase amor a las instituciones, respeto a las autoridades o deseos por el bien de sus conciudadanos. En consecuencia, la manera de distinguir a "los hombres que sólo mirasen la causa pública" de los que no lo hacían residía en el trabajo, en las propiedades o en las rentas consecuentes. Si el gobierno debía instruir a los ciudadanos "en las verdaderas virtudes sociales", éstos, en tanto miembros de una sociedad, debían contribuir con bienes físicos, industriales o intelectuales para originar la riqueza común. Tal intercambio definía la actividad laboral como un acto de consagración al servicio de la patria y, por tanto, la identificaba como una vía de adquisición de la ciudadanía. Frente a esta concepción, ¿de qué modo los indios servían y eran útiles a la nación y cómo demostraban su espíritu de industria para ser asumidos como patriotas?

La respuesta inicial a este interrogante aludía fundamentalmente en el trabajo agrícola y ganadero. Respecto a él, en opinión de los asamblearios la población india estaba expuesta a dos males: primero, un mundo rural atrasado resultado de la desidia histórica colonial y de la guerra; y, segundo, un posible destino de vagancia y ociosidad debido a la ignorancia técnica y a los malos hábitos. Para resolver esa situación resultaba imprescindible "un impulso animador y benéfico" procedente de la acción moralizadora del Estado. Si la riqueza nacional equivalía a la prosperidad pública y ésta dependía de la población, había que lograr que ésta adquiriera los medios necesarios para tornarse instruida e industriosa. Pero para que el Estado pudiera estimular y ayudar a los indígenas a aprovechar sus tierras era básico que dispu-

Bosquejo Estadistico de Bolivia. La Paz: UMSA, pp. 313-323; Ramón Sotomayor Valdés (1874): Estudio histórico de Bolivia bajo la administración de general D. José María de Achá con una introducción que contiene el compendio de la guerra de independencia y de los gobiernos de dicha República hasta 1861. Santiago: Imp. Andrés Bello, pp. 17-18. 
siera de recursos públicos. Como uno de los modos de obtenerlos era la recaudación hacendística, ésta adquirió un papel central en la definición de la ciudadanía. La necesidad de ingresos estables conllevó que, tras el fracaso del gobierno de José Antonio de Sucre (18261829) en crear una contribución directa única, Andrés de Santa Cruz (1829-1839) restituyera el tributo indígena abolido por las Cortes de Cádiz, convirtiéndose éste en la fuente más estable de financiación estatal (Sánchez-Albornoz 1986: 190-199; Lofstrom 1983; Platt 1982; 1986; Millington 1995).

El tributo indígena colocó a los indios en una posición central en la consolidación nacional del Estado en su calidad de benefactores del mismo. Ello favoreció dos fenómenos interrelacionados de reafirmación: grupal y estatal. Respecto a la primera, dado que los indígenas constituían uno de los colectivos que más necesitaban aprovecharse de la capacidad redentora del Estado, el que ellos fueran los pagadores del tributo les convertía en merecedores legítimos de las bondades de éste. De ello resultó la aplicación del principio de reciprocidad de derechos y deberes según el que si había la obligación de dar y de servir más, había también el derecho de pedir y reclamar más. Por tanto, ya que "los ciudadanos más pobres y laboriosos" del país, como eran los indígenas en su calidad de comunarios, de colonos de fincas o de forasteros sin tierras, pagaban sus contribuciones, debía desarraigarse de la sociedad la idea de que tributar era contrario al ciudadano libre. Como los que tributaban contribuían "al fondo público para las atenciones y gastos de la nación", tal acto les convertía en hombres necesarios y virtuosos, "verdaderos ciudadanos útiles al Estado". Pero como eran percibidos "por sus útiles ocupaciones, por su condición miserable y por su falta de ilustración" necesitados de guía, tal reconocimiento ciudadano fue establecido en términos de protección. De ahí que con el objetivo de restablecer a los indios "su dignidad como ciudadanos" no sólo se emitieran decretos tendentes a impedir su trabajo gratuito, a asegurarles la propiedad de la tierra o garantizarles que sus intereses comunes estuviesen representados por medio de apoderados nombrados por ellos, sino que también se reestableciera en 1837 del Ministerio del Protector de Indígenas, derogado el 7 de julio de 1838 por no responder a las expectativas gubernamentales. Tales medidas fueron interpretadas como un apoyo extralocal que asegurase a 
las comunidades indias el disfrute de sus posesiones territoriales y de las ventajas jurisdiccionales que conllevaban.

Esto resultaba en cierta forma acuciante debido a la supresión de los ayuntamientos constitucionales llevada a cabo por el gobierno de Sucre. La reducción de sus funciones a las de ornato y policía y la consiguiente pérdida de competencias, como las de crear impuestos municipales, impartir justicia o, incluso, marcar actividades colectivas, implicó que la población afectada buscara que el Estado les proporcionara otro tipo de régimen autonómico. Éste consistió en un reconocimiento legal de prácticas territoriales de ejercicio del poder a través de la preservación de sus terrenos y de rescatar las comunidades indígenas como instituciones corporativas que se mantenían como tales debido a la indefensión de sus miembros. A cambio, tal restitución territorial confirmaría la creación de un entramado social de coerción encaminado al disciplinamiento de las fuerzas locales en términos de lealtad. Por ello, tal política protectora no resultaba contraria a los principios liberales de desarraigo de todo corporativismo de antiguo régimen, sino que se insertaba en la lógica de que el Estado debía propiciar y garantizar la adquisición entre los bolivianos de las condiciones morales y materiales que les redimieran del pasado colonial y les tornara sujetos amantes del progreso y orden del país, de las leyes, de la buena moral y de la civilización.

Respecto a la reafirmación estatal, tras los desórdenes de la guerra, la red de recaudación pudo reconstruirse con relativa eficacia gracias a la autonomía de facto de los tesoros departamentales, cuya capacidad de gasto, empezando por el pago de sus propios haberes, dependía directamente de lo que ellos mismos recaudasen. Si bien este control de las autoridades locales del medio rural garantizaba el enriquecimiento del Estado, también hacía peligrar su acción de reconquista territorial y jurisdiccional, por lo que éste necesitaba tanto mantener algún nexo directo con las entidades que originaban la riqueza, como asegurarse que siguieran produciendo dicho bien. Ello se tradujo en dos acciones básicas. Por un lado, el Estado para poder reconstruir el tributo indígena debió renovar las exenciones y los privilegios gozados por los tributarios en la época colonial y también exonerarlos de otros impuestos -alcabala- y del servicio militar. Por otro, el Estado para aumentar la recaudación necesitaba que dicha población hiciera más productivos sus terrenos y dinamizase el mercado con la comer- 
cialización de parte de sus cosechas, por lo que requería ampliar el número de tributarios mediante nuevos repartos de tierra, resolver el problema de la población rural que se "desincribía" de su comunidad originaria para escapar del control fiscal, empadronar a los contribuyentes y evitar la venta de los terrenos. El resultado inmediato de tales acciones fue que el fortalecimiento de la capacidad económica del Estado conllevara el fortalecimiento de las comunidades. En la medida en que el Estado no era autónomo en sus ingresos estaba obligado a pactos fiscales con la sociedad civil, con lo que la contribución aseguraba a la población indígena que éste estuviese de alguna forma bajo su control. Por tanto, la reivindicación india de sus privilegios y propiedades fue potenciada y propiciada por el poder central siempre que ello reafirmase la autoridad gubernamental y la eficacia de las instituciones del Estado en adquirir presencia territorial y en rearticular una administración nacional.

En vista de lo anterior, aunque este intercambio podría entenderse como la prolongación de la dualidad fiscal entre españoles e indios, el mantenimiento del tributo no supuso un mero retorno al pasado. Fue el medio a través del que el Estado encontró una vía de financiamiento que lo fortaleciera para poder cumplir con su papel de ente benefactor de la sociedad a la que debía dignificar mediante su acción pedagógica. Sin fondos en el Tesoro Público resultaba imposible la construcción de una nueva sociedad. Como las circunstancias habían hecho que los indígenas fueran los proveedores del Estado a través de realizar un servicio estatal llamado tributo, éste actuó como su protector no sólo por asumirlos como ciudadanos productivos, sino también porque al desempeñar tal papel aseguraban que el Estado pudiera ejercer su objetivo de vertebrador nacional y de sanador institucional y, en consecuencia, legitimar su autoridad política y pública. Luego la protección del Estado expresada en facilitar a las comunidades la renovación de los derechos territoriales, no era un resabio colonial, sino una recompensa al patriotismo republicano indio. $\mathrm{Y}$ éstos no se aferraron a la memoria idealizada del "viejo Estado colonial", sino que reivindicaron sus ventajas corporativas como ciudadanos útiles y laboriosos de la República. 


\section{Los patriotas mueren por Bolivia: ciudadanos armados 6}

A medida que el tributo perdió fuerza como elemento de legitimación ciudadana de la población indígena (Klein 1995; Mitre 1981), ésta se vio obligada a recurrir a otros componentes de la ciudadanía cívica, como el de soldado de milicias/civil armado, para demostrar que merecía el disfrute de la ciudadanía bajo las nociones de servicio y utilidad a la sociedad. Si en las primeras décadas de vida republicana, el problema de cómo sanear la hacienda pública y lograr la estabilidad financiera había convertido al tributo en un elemento central tanto del proceso de institucionalización del Estado como del de definición del indio como ciudadano, a finales de la década de 1850 la situación comenzó a variar. Mientras en un inicio el Estado debía actuar de motor transformador de la sociedad, en un segundo momento sólo debía programar una oferta de bienes y servicios útiles a tal fin y dejar que fuese esa sociedad la que dirigiera el bienestar y el beneficio de toda la comunidad. Como a mediados del siglo XIX Bolivia no había alcanzado las cotas de progreso esperadas tras la independencia, aquellos colectivos a los que se suponía que el Estado había otorgado mayores atenciones fueron culpados de entorpecer la mejora nacional. Dado que los indígenas habían mantenido privilegios coloniales en lo relativo a la tierra y a la jurisdicción sobre la misma a cambio de ser tributarios y de hacerse cargo de la modernización del agro, el hecho de que no se hubiera producido la revolución agraria esperada hizo que el dinero procedente del tributo dejase de verse como crédito industrial y que la estructura comunitaria se asumiese como una rémora arcaica que impedía la riqueza nacional. Ello provocó que el indio pasase de ser concebido como un trabajador productivo, generador de impuestos y de ganancia agrícola, a un individuo que debía ser incorporado humanitariamente a la sociedad civilizada desvinculándole de sus tradiciones y prácticas, ya que se había demostrado que la conservación de éstas atentaba contra el desarrollo del país. Como la mercantilización de las relaciones de autoridad y poder en nombre de construir una sociedad con "hombres libres e individuales" amenazaba el entramado comunitario y su estructura regional, hubo rechazo indígena a secundar las reformas agrarias. Tal actitud fue interpretada como procedente

6 Este apartado sintetiza los argumentos expresados en cuatro artículos: Irurozqui 2005a: 285-320; 2006a: 32-55; 2006b: 35-66. 
de una colectividad precivilizada, ignorante y bárbara $\mathrm{y}$, por tanto, reafirmada la oferta criolla de que había que transformar las formas de organización rurales para evitar el estancamiento económico. Así, en la década de 1860 se discutió sobre las formas, mecanismos y estrategias más eficaces para lograr la desaparición de las comunidades (Langer/Jackson 1990; Peralta/Irurozqui 2000).

Fue en este contexto donde la figura del indio soldado de milicias cobró importancia como categoría de revitalización ciudadana. Esto sucedió tanto porque los indígenas habían incorporado las claves de utilidad de la ciudadanía y se reinventaban una función de servicio a la sociedad, como porque las reformas agrarias amenazaban con minar la estrategia de institucionalización del Estado en el medio local. Si en las primeras décadas republicanas los indios ayudaban a reforzar la autoridad del Estado mediante el trabajo agrícola/minero y el tributo, en la segunda mitad del siglo XIX lo hicieron mediante su conversión en fuerzas auxiliares en conflictos civiles que les permitían ejercer de patriotas. Ya que el pago del tributo les exoneraba de ser enganchados como soldados de línea, actuaron en calidad de soldados de milicias, categoría vinculada en tiempos coloniales a la vecindad y síntesis del "ciudadano en armas" defensor de la libertad de la República. Ello no sólo les permitía gozar de los derechos electorales aunque estuviesen de servicio -algo que no ocurría por ley con los soldados de enganche o asalariados-, sino que les confirmaba como detentadores de un deber que se concebía también como un privilegio que honraba a su titular. Este ejercicio de la violencia manifestado en términos de utilidad y cooperación a favor de la patria no sólo constituía en sí mismo una muestra de lealtad nacional, sino que adquiría un grado mayor de importancia nacional en la medida en que posibilitaba un objetivo institucional: la "domesticación" de los poderes locales y la rearticulación de una administración nacional.

Además de las montoneras indígenas en tiempos de los presidentes Isidorio Belzu y José María Linares (Calderón Jemio 1993; Schelchkov 2007), un ejemplo de lo anterior lo materializó la población aymara del altiplano paceño gracias a su participación en la guerra civil de $1870^{7}$ en calidad de ejército auxiliar de las fuerzas encabezadas por

7 La documentación referente a los acontecimientos de 1870-1871 pertenece en su mayoría a Archivo de La Paz/CN. Expedientes Judiciales 1854/1898, ff. 1-230. 
Agustín Morales (1871-1872) contra el presidente Mariano Melgarejo (1866-1870). Su conversión en nacionales armados obedecía al doble propósito de, por un lado, conservar las tierras de comunidad y de restaurar un poder jurisdiccional sobre las mismas en clave republicana y, por otro, transmutar una identidad colectiva vilipendiada, como era la de indiada, por otra que resumiese los nuevos valores nacionales. Tal pretensión recibió el beneplácito de los revolucionarios por dos razones.

Respecto a la primera, éstos opinaban que la participación india en el conflicto no sólo les posibilitaría la recuperación de sus propiedades, sino que la restitución de su medio de vida -la tierra- les daría de nuevo la oportunidad de conformarse en individuos útiles a la nación porque contribuirían a su progreso material y porque cumplirían con el deber nacional de la salvación armada de la patria. Tal gesto, en la medida que presuponía contribución a una causa nacional en términos de generosidad cooperativa, les brindaba una posibilidad de reincorporación pública mediante su redignificación identitaria. Ésta consistía en volver a adquirir una perdida imagen grupal compatible con la unidad nacional que contradijese su fundamentalismo comunitario y que combatiese la heterogeneidad étnica que limitaba su absorción nacional. A cambio de no permanecer indiferentes a la defensa de la democracia y de asumir a la misma como un deber patriótico ante el que sería válido cualquier sacrificio -donaciones tributarias y de víveres y "hacer la guerra sin tregua al enemigo"- obtendrían una liberación definitiva de los resabios coloniales que les impedían obtener el refrendo social de su estatus legal como ciudadanos. En este sentido, los actos bélicos indígenas expresaban una voluntad de homogeneización cultural basada en la cohesión social de sus integrantes. Ésta quedaba manifiesta en la asunción por parte de los combatientes de una causa diferente a la propia y en una autoinmolación grupal al servicio de un proyecto general.

Respecto a la segunda razón, en su esfuerzo de penetrar y de reestructurar la administración de lo público local, el Estado requirió estratégicamente explicitar su preeminencia en el control de las poblaciones a través de una alianza con el mundo indígena, visto como fuerza organizada que le ayudase a equilibrar a su favor el ejercicio de la autoridad. Tal requerimiento coincidía con la necesidad de las comunidades de un apoyo extralocal que les evitase entrar en el ámbito 
de control privado de los organismos locales y ser gobernadas como "cosa particular". Por tanto, la reivindicación indígena de sus derechos y propiedades fue potenciada y propiciada por el poder central siempre que ello supusiese una demostración con éxito de la capacidad de injerencia y de arbitraje del Estado en el mundo local. En este sentido, los indígenas ganaron presencia pública no sólo por participar como ejército auxiliar en un conflicto que les permitió ejercer de patriotas, sino también por compartir el objetivo institucional de reforzar la potestad estatal en el medio rural.

Sin embargo, a partir de la década de 1880, aunque la ciudadanía siguió vinculada a la acción patriótica, este comportamiento ya no resultaba suficiente ni satisfactorio. Tras la derrota de la Guerra del Pacífico (1879-1883) y en un contexto internacional influenciado por el pensamiento de jerarquización racial legitimado por la ciencia de la época, el reconocimiento público comenzó a desvincularse del refrendo comunitario y de la contribución y los méritos locales, característicos de la ciudadanía cívica, para medirse en función de criterios de estricta adecuación a un modelo de comportamiento social asentado en la idea de progreso, propios de la ciudadanía civil. Este proceso se tradujo públicamente en un mayor esfuerzo gubernamental en exigir y garantizar un estricto cumplimiento de los requisitos ciudadanos, vinculándose los controles de reconocimiento público al criterio de civilización en términos de homogeneidad cultural. Ahora, el control en la determinación de si un sujeto era o no ciudadano ya no se situaba en la demostración por parte del aspirante de utilidad, cooperación y compromiso patrióticos, sino que radicaba en su grado de civilización o en su posibilidad de alcanzarla, siendo individuos ajenos a los que se querían ciudadanizar quienes debían estimarlo.

Esas variaciones tuvieron incidencia directa en el modo en que fue percibida socialmente la participación indígena en otra guerra civil, la Guerra Federal de 1899. ${ }^{8}$ En este caso el Partido Liberal se sub-

8 El material documental referente a los acontecimientos de 1899: Alberto Rodríguez Forest (1999): Documentos para la Historia de la Guerra Civil 1898-1899. Sucre, Gobierno Municipal de Sucre: ALP. Proceso Mohoza (1901-194); Bautista Saavedra: Defensa del abogado Bautista Saavedra pronunciada en la Audiencia del 12 de octubre de 1901. La Paz: Tip. Artística Velarde, Aldazosa y Ca (1902); Bautista Saavedra (1903): "La criminalidad aymara en el proceso de Mohoza". El ayllu. La Paz. Natalio Fernández Antezana (1905): La hecatombe de Mohoza. La supuesta complicación del cura Jacinto Escobar y la comprobación 
levó contra el Partido Conservador en el gobierno y contó con la colaboración de parte de la población india del altiplano en calidad de ejército auxiliar (Condarco Morales 1983; Larson 2002; Mendieta 2007). Pero, aunque los rebeldes accedieron al poder gracias a la actuación de los indios, acabado el conflicto éstos en vez de ser recompensados por ello fueron objeto de un proceso de criminalización. Si en 1870 el ejercicio de la violencia armada había otorgado a este colectivo la posibilidad de transformar en nacionales sus peticiones corporativas, en 1899 sus exigencias nacionales se interpretaron como grupales y segregadoras. Aunque tras los acontecimientos de $1870 \mathrm{se}$ sabe aún poco de los términos en los que se construyó la convivencia local en un contexto definido por el valor de la homogeneidad, a lo largo de las décadas de 1880 y 1890 la población indígena volvió a desdibujarse identitariamente como la indiada. Como esta categorización ponía en duda su compromiso nacional y, por tanto, la legitimidad de su acceso a la ciudadanía, el conflicto de 1899 constituyó otra oportunidad de redención nacional para este colectivo. Su actuación como ejército auxiliar de los liberales les ofreció una nueva ocasión para liberarse del bagaje arcaico que les impedía ser socialmente percibidos como agentes de progreso. De ahí que para demostrar ser merecedores de tal estatus recurrieran de nuevo a convertirse en soldados de milicias, ya que esa actividad les permitía hacer dos demostraciones públicas: por un lado, la exhibición de un esforzado sentimiento patriota y una disciplina cívica, síntesis de su compromiso con la patria; por otro, la reinvención de su utilidad al Estado en calidad de articuladores locales a través de los municipios. Respecto a este segundo aspecto, no se olvide que a partir de la experiencia de la Constitución de Cádiz en el contexto independentista los indígenas habían considerado a estas entidades como una fórmula representativa capaz de conciliar lo liberal con sus demandas corporativas. Esa convicción, unida a la campaña proselitista liberal en el agro desarrollada desde de la década de 1880 y a la cercanía del municipalismo con los dictados federales, les hizo defender que la conservación de espacios y privilegios grupales no dependería del éxito de una hipotética rearticulación administrativa estatal, sino de que gestionaran tal proceso en tanto 
miembros de municipios nacionales. Sin embargo, terminada la guerra no sólo no fueron reconocidos como "el pueblo armado", sino que acusados de iniciar una "guerra de razas" se les condenó pública y judicialmente por traición a la patria. ¿En términos de ciudadanía, qué había cambiado?

Si en 1870 la ciudadanía se entendía como una conquista individual que requería esfuerzo y disciplina y a la que podían aspirar todos los sujetos que estuviesen dispuestos al sacrificio de sus ambiciones personales por el bien público, en 1899, en un contexto marcado por pérdidas territoriales y bajo la influencia de corrientes de pensamiento que jerarquizaban a la población en virtud de su origen étnico, el progreso nacional se interpretaba amenazado más que nunca por todo aquello que afectase la cohesión nacional. Ello provocó que dejase de confiarse en el poder benéfico de las instituciones republicanas y en la fuerza redentora del patriotismo para dignificar a la población. En su lugar se asentó la idea de que, a causa de taras ancestrales y de un determinado origen étnico, muchos habitantes de Bolivia resultaban refractarios a la civilización y, con ello, al progreso moral y material del país. De ahí que en 1899 el ejercicio de violencia revolucionaria tornase a los indios en traidores de la patria -condición legal de perdida de ciudadanía-, en contraste con lo ocurrido en 1870-71 cuando los había convertido en patriotas. El detonante de esta inversión identitaria fue la masacre de Mohoza, en la que el 29 y 30 de febrero de 1899 ciento veinte integrantes del batallón liberal Pando, varios vecinos del pueblo y hacendados locales fueron victimados en esta localidad y en sus inmediaciones por un grupo de indios liderado por Lorenzo Ramírez, lugarteniente del jefe de ejército auxiliar indio Zarate Villca. Tal acto conmocionó a la opinión pública, no tanto por su violencia, sino porque los autores del mismo formaban parte de la fuerza indígena que cooperaba con los liberales.

Aunque a raíz de matanza el jefe liberal Manuel Pando trato de disminuir las competencias militares de sus aliados indios, su ayuda siguió siendo solicitada contra el enemigo y sólo después de terminada la guerra se tomaron medidas policiales, carcelarias y judiciales contra ellos. De nada sirvieron los esfuerzos por parte del líder indígena de mostrar que el triste y excepcional suceso de Mohoza no había impedido a los liberales ganar la guerra gracias al apoyo de sus efectivos. El resultado fue la anulación discursiva de los méritos bélicos que en 
1870 habían otorgado a los indios reconocimiento nacional, de manera que el atentado contra el batallón liberal les hizo bolivianos indignos de participar en la construcción nacional. Los juicios de Mohoza y Peñas acaecidos entre 1901 y 1904 fueron un escenario donde no sólo se juzgó y condenó a los implicados en las matanzas, sino a la población aymara en su conjunto. Ésta quedó invalidada públicamente bajo la acusación de desarrollar iniciativas salvajes, brutales y sádicas contra el resto de los bolivianos, siendo tales actividades prueba tanto de su falta de civilización, como de su incapacidad congénita para adquirirla. Consecuencia del juicio y la condena de los implicados fue una desciudadanización discursiva de la población indígena basada en el principio de que su arcaísmo cultural los incapacitaba como sujetos nacionalmente confiables porque los hacía vulnerables a la traición y a la destrucción del país. La ayuda prestada a los liberales en su triunfo contra el gobierno quedó, así, oficialmente olvidada al igual que negada la responsabilidad de éstos en la movilización india. En su lugar se erigió la matanza del batallón Pando como la síntesis de todo lo que podía llegar a ocasionar los indígenas si tenían presencia política y adquirían poder público. No importó el confuso conflicto rural entre militares, vecinos de los pueblos e indígenas que encerraba la masacre, ni tampoco la coparticipación de los últimos en todos los sucesos. La matanza de Mohoza, interpretada no sólo como una traición al Partido Liberal, sino como una traición de los indios a Bolivia, a cuya población odiaban y querían masacrar en venganza a siglos de opresión, condenó a la población aymara a una cuarentena y minusvalía públicas. Convertidos discursivamente en un colectivo bárbaro, sangriento, inasimilable por la civilización occidental, y, por tanto, necesitado de una tutela disciplinadora de su potencial arcaico, los indios fueron objeto de una política de invisibilización pública. Ésta se expresó a través tanto de condenarles a una criminalidad innata, explicitada en su deseo de una guerra de razas, como de convertirles en una población eternamente infantil incapaz de comprender el juego político. Ambas posturas, al acusar a la población india del pecado de heterogeneidad cultural y responsabilizarla de la ausencia de cohesión social y tradición cultural, la negaban un papel activo en la confección de la nación y dejaban recluida en una imagen esencialista y apolítica que la tornaba en objeto de políticas públicas. 


\section{Conclusiones}

A inicios del siglo XX y con el telón de fondo de la matanza de Mohoza, los indios fueron declarados inhábiles para participar en calidad de sujetos políticos en la nación boliviana, debido a su incapacidad para desprenderse de sus costumbres arcaicas y de un pasado de degeneración racial. Si bien esta afirmación obedeció a una lógica discursiva elitista encaminada a recrear jerarquías sociales y a disciplinar políticamente a los sectores populares a través de clichés étnicos, gran parte de la literatura y de la historiografía de los siglos XX y XXI la asumió como cierta. Consecuencia de ello ha sido la hegemonía de tópicos historiográficos relativos tanto a la exclusión absoluta de los indígenas de la sociedad, como a su desinterés en insertarse en la nación e influir en el desarrollo de políticas públicas.

Con el objetivo de favorecer una reflexión historiográfica sobre las consecuencias políticas, las fracturas sociales y las distancias culturales que conllevó y conlleva la invisibilización o el falseamiento del pasado indígena en clave victimista (conjugación de culpa, menosprecio y oportunismo político), este texto ha incidido en cómo esta población se apropió de las lógicas y las ideologías implícitas en el proyecto nacional y las recreó para obtener oportunidades de existencia social individual y corporativa a través tanto de la restitución de recursos comunitarios y del fortalecimiento de espacios jurisdiccionales, como de una resignificación identitaria grupal en clave republicana. Esto lo hizo mediante el desempeño de tres funciones cívicas: trabajador, contribuyente y soldado de milicias. El ejercicio de tales actividades, desarrollado bajo los parámetros patrióticos de utilidad, solidaridad y servicio a la sociedad, les permitió autorreconocerse y ser reconocidos por la sociedad como ciudadanos, más allá de lo que establecieran las leyes al respecto. En la medida en que este estatus implicaba que se habían reinventado a sí mismos como servidores del Estado, evidenciaba también que no vivieron de espaldas al proceso de construcción nacional ni fueron ajenos a las concepciones, proyectos o empresas políticas decimonónicas. Se constituyeron en sujetos sustanciales en la institucionalización/rearticulación territorial del Estado gracias a asumir como propia la narrativa ciudadana de cooperación nacional y a proyectarla en su defensa grupal bajo la consideración que ésta acción era compatible con los intereses nacionales. Sin embargo, el hecho de 
que la ciudadanía fuera percibida como una facultad que debía ser aprendida y un privilegio a ganarse tornó el estatus adquirido en contingente. Aunque los valores que rigieron a la ciudadanía cívica-de compromiso patriótico demostrado en los deberes- y a la ciudadanía civil -de superioridad civilizatoria para ejercer derechos- fueron diferentes, no lo fue el hecho de que en ambos casos la ciudadanía se asumió como un bien de conquista al que todos tendrían acceso siempre y cuanto sufriesen un proceso de transformación individual y colectiva. De ahí que fuera posible la elaboración de una narrativa oficial que descalificara la capacidad política indígena bajo la acusación de romper la unidad nacional.

Si bien ya se ha señalado con anterioridad el carácter nocivo en términos de cohesión social de esa elaboración discursiva, no hay que olvidar que se trató de un discurso y que como tal no trabó que la población indígena continuara interviniendo en la definición de la nación, como lo prueba el hecho del progresivo aumento de la presencia indígena en la vida asociativa, en el sistema de partidos y en la estructura gubernamental (Irurozqui 2000; Gotkowitz 2007; Mendieta 2008, Brienen 2004). Su descalificación social generó, paradójicamente, una mayor necesidad de conquista del espacio público nacional en calidad de legítimos miembros del mismo. En este sentido, el siglo XIX, con su multifacética experimentación ciudadana, ofrece uno de los escenarios donde los indígenas aprendieron, ejercieron y generaron las lógicas nacional y nacionalista.

\section{Bibliografía}

Barragán, Rossana (2000): "Tramas, dramas, epopeyas y mitos en las historias bolivianas del siglo XIX". En: Historias... de mitos de ayer y hoy. Revista de la Coordinadora de Historia, pp. 51-94.

Brienen, Marten (2004): Education and Nation Building in Bolivia, 1932-1952. Tesis Doctoral. Leiden: Universidad de Leiden.

Calderón Jemio, Raúl (1993): La rebelión de 1858-1860 en la provincial de Omasuyos. La Paz: Ediciones Gráficas.

Condarco Morales, Ramiro (1983): Zárate. El temible Willka. Historia de la rebelión indigena de 1899. La Paz: Imp. Renovación.

García Jordán, Pilar (2006): "Yo soy libre y no indio: soy guarayo”. Para un historia de los guarayos, 1790-1948. Lima: IFEA/TEIAA/PIEB/IRD. 
Gotkowitz, Laura (2007): A Revolution for our Rights. Indigenous Struggles for Land and Justice in Bolivia 1880-1952. Durham/London: Duke University Press.

Irurozqui, Marta (2000): A bala, piedra y palo. La construcción de la ciudadanía política en Bolivia, 1825-1952. Sevilla: Diputación de Sevilla.

- (2003): "El bautismo de la violencia. Indios patriotas en la revolución de 1870". En: Salmón, Josefa/Delgado, Guillermo (eds.): Identidad, ciudadanía y participación popular desde la colonia hasta el siglo XX. La Paz: Plural, pp. 115-150.

- (2005a): "Los hombres chacales en armas. Militarización y criminalización indígenas en la Revolución Federal de 1899". En: Irurozqui, Marta (ed.): La mirada esquiva. Reflexiones históricas sobre la interacción del Estado y la ciudadanía en los Andes (Bolivia, Ecuador y Perú), siglo XIX. Madrid: CSIC, pp. 285320 .

- (2005b): La ciudadanía en debate en América Latina. Discusiones historiográficas y una propuesta teórica sobre el valor público de la infracción electoral (Documento de Trabajo, 139). Lima: IEP.

- (2006a): "Sobre el tributo y otros atributos ciudadanos. Sufragio censitario, fiscalidad y comunidades indias en Bolivia, 1825-1839". En: Bicentenario. Revista de Chile y de América (Santiago de Chile), 5, 2, pp. 35-66.

- (2006b): “¿Ciudadanos armados o traidores a la patria? Participación indígena en las revoluciones bolivianas de 1870 y 1899”. En: Iconos. Revista de Ciencias Sociales, 26, pp. 35-46.

- (2008a): "El espejismo de la exclusión. Reflexiones conceptuales acerca de la ciudadanía y el sufragio censitario a partir del caso boliviano". En: Ayer, 70, 2, pp. 57-92.

- (2008b): "El pueblo soberano versus la plebe proselitista. Discurso historiográfico y etnicización política en Bolivia, 1825-1922". En: Palacios, Guillermo (ed.): Historias nacionales y la construcción de los Estados liberales modernos en América Latina durante el siglo XIX. México, D.F.: CM.

Klein, Herbert (1995): Haciendas y ayllus en Bolivia, siglos XVIII y XIX. Lima: IEP.

Langer, Erick/Jackson, Robert (1990): "El liberalismo y el problema de la tierra en Bolivia, 1825-1820". En: Siglo XIX, 5, 10, pp. 9-32;

Larson, Brooke (2002): Indígenas, elites y Estado en la formación de las repúblicas andinas. Lima: PUCP/IEP, pp. 145-179.

Lofstrom, William Lee (1983): El mariscal Sucre en Bolivia. La Paz: Editorial e Imprenta Alenkar Lda.

Mendieta, Pilar (2007): De la alianza a la confrontacion. Pablo Zarate Willka y la rebelión indígena de 1899 en Bolivia. Tesis Doctoral. Lima: Universidad Nacional Mayor de San Marcos.

- (2008): "Política y participación indígena en Bolivia. Una mirada desde la historia: siglos XIX-XX". En: Continuidad y cambio en el orden político. Las transiciones en el contexto constituyente. La Paz: Instituto Prisma.

Millington, Thomas (1995): Políticas de la deuda después de la Independencia. El conflicto del financiamiento en Bolivia. La Paz: BCB.

Mitre, Antonio (1981): Los patriarcas de la plata. Lima: IEP. 
Peralta, Víctor/Irurozqui, Marta (2000): Por la concordia, la fusión y el unitarismo. Estado y caudillismo en Bolivia. Madrid: CSIC.

Platt, Tristan (1982): Estado boliviano y ayllu andino. Tierra y tributo en el norte de Potosí. Lima: IEP.

- (1986): Estado tributario y librecambismo en Potosí (siglo XIX). Mercado indígena, proyecto proteccionista y lucha de ideologías monetarias. La Paz: Hisbol.

Quijada, Mónica (2004): “Construcción nacional y 'pueblos originarios': un camino no lineal entre la homogeneización y la diversidad de ayer a hoy”. En: Tribuna Americana, 3, pp. 9-23.

Salmón, Josefa (1997): El espejo indígena. El discurso indigenista en Bolivia 1900-1956. La Paz: Plural.

Sánchez-Albornoz, Nicolás (1986): Indios y tributo en el Alto Perú. Lima: IEP.

Schelchkov, Andrey A. (2007): La utopía social conservadora en Bolivia: el gobierno de Manuel Isidoro Belzu 1848-1855. Moscú: Academia de Ciencias. 
